\title{
THE PAULSEN PROBLEM IN OPERATOR THEORY
}

\author{
Jameson CAHill and Peter G. CASAZZA
}

\begin{abstract}
The Paulsen Problem in Hilbert space frame theory has proved to be one of the most intractable problems in the field. We will help explain why by showing that this problem is equivalent to a fundamental, deep problem in operator theory. This answers a question posed by Bodmann and Casazza. We will also give generalizations of these problems and we will spell out exactly the complementary versions of the problem.
\end{abstract}

Mathematics subject classification (2010): 42C15, 46C05.

Keywords and phrases: Frame theory, Paulsen Problem, Projection Problem.

\section{REFERENCES}

[1] M. Argerami and P. Massey, Towards the Carpenter's theorem, Proc. Amer. Math. Soc. 137 (2009), 3679-3687.

[2] J. Antezana, P. Massey, M. Ruiz, D. Stojanoff, The Schur-Horn theorem for operators and frames with prescribed norms and frame operator, Illinois J. Math. 51 (2007), 537-560.

[3] M. Argerami, P. Massey, A Schur-Horn theorem in $\mathrm{II}_{1}$ factors, Indiana Univ. Math. J. 56 (2007), 2051-2059.

[4] W. ARVESon, Diagonals of normal operators with finite spectrum, Proc. Natl. Acad. Sci. USA 104 (2007), 1152-1158.

[5] W. ARVESON, R. KADISON, Diagonals of self-adjoint operators, Operator theory, operator algebras, and applications, 247-263, Contemp. Math., 414, Amer. Math. Soc., Providence, RI, 2006.

[6] R. Balan, Equivalence relations and distances between Hilbert frames, Proc. Amer. Math. Soc. 127, 8 (1999), 2353-2366.

[7] B. Bodmann AND P. G. CASAZZA, The road to equal norm Parseval frames, Journal of Functional Analysis 258, 2 (2010), 397-420.

[8] M. BowniK, J. JASPER, Characterization of sequences of frame norms, J. Reine Angew. Math., to appear.

[9] P. G. CASAZZA, M. Fickus And D. Mixon, Auto-tunning unit norm tight frames, Appl. and Comp. Harmonic Anal. 32 (2012), 1-15.

[10] P. G. Casazza, M. Fickus, M. Leon, J. Kovačević, J. C. Tremain, A physical interpretation for finite tight frames, Appl. and Comp. Harmonic Anal. (2006), 51-78.

[11] P. G. CASAZZA AND J. J. KovaČEvić, Uniform tight frames with erasures, Advances in Computational Mathematics 18, 2-4 (2003), 93-116.

[12] P. G. CASAZZA AND G. KUTYNIOK, A generalization of Gram-Schmidt orthogonalization generating all Parseval frames, Advances in Computational math. 18 (2007), 65-78.

[13] P. G. CASAZZA AND M. LeOn, Existence and construction of finite tight frames, J. Concr. Appl. Math 4, 3 (2006), 277-289.

[14] P. G. CASAZZA AND M. LEON, Existence and construction of finite frames with a given frame operator, International Journal of Pure and Applied Mathematics 63, 2 (2010), 149-158.

[15] O. Christensen, An Introduction to Frames and Riesz Bases, Birkhaüser, Boston (2003).

[16] J. H. Conway, R. H. Hardin, N. J. A. Sloane, Packing lines, planes, etc.: packings in Grassmannian spaces, Experiment. Math. 5, 2 (1996), 139-159.

[17] I. C. Gohberg AND A. S. MARKuS, Some relations between eigenvalues and matrix elements of linear operators, Mat. Sb. (N.S.) 64 (1964), 481-496. 
[18] D. Han and D. Larson, Frames, Bases and Group Representations, Mem. Amer. Math Soc. 147 (2000).

[19] A. HoRN, Doubly stochastic matrices and the diagonal of a rotation matrix, Amer. J. Math. 76 (1954), 620-630.

[20] R. A. Horn And C. R. Johnson, Matrix analysis, Cambridge University Press, 1985.

[21] A. J. E. M. JAnssen, Zak transforms with few zeroes and the tie, In Advances in Gabor Analysis, H.G. Feichtinger and T. Strohmer (eds.), pages 31-70, Birkhäuser, Boston (2002).

[22] J. JASPER, The Schur-Horn theorem for operators with three point spectrum, Preprint.

[23] R. KAdison, The Pythagorean theorem. I. The finite case, Proc. Natl. Acad. Sci. USA 99 (2002), 4178-4184.

[24] R. KAdison, The Pythagorean theorem. II. The infinite discrete case, Proc. Natl. Acad. Sci. USA 99 (2002), 5217-5222.

[25] K. Kornelson, D. Larson, Rank-one decomposition of operators and construction of frames, Wavelets, frames and operator theory, 203-214, Contemp. Math., 345, Amer. Math. Soc., Providence, RI, 2004.

[26] V. Kaftal AND G. Weiss, An infinite dimensional Schur-Horn theorem and majorization theory, J. Funct. Anal., to appear.

[27] A. Neumann, An infinite-dimensional version of the Schur-Horn convexity theorem, J. Funct. Anal. 161 (1999), 418-451.

[28] I. SCHUR, Über eine Klasse von Mittelbildungen mit Anwendungen auf die Determinantentheorie, Sitzungsber. Berl. Math. Ges. 22 (1923), 9-20. 